\title{
LAS CLÁUSULAS LIMITATIVAS, EXONERATIVAS O AGRAVANTES DE RESPONSABILIDAD EN MATERIA CONTRACTUAL. VALIDEZ Y LÍMITES
}

\author{
LIMITATION, EXONERATION AND AGGRAVATION OF LIABILITY \\ CLAUSES. VALIDATION AND LIMITS.
}

\author{
Joel GonZÁlez CASTILlo*
}

\begin{abstract}
RESUMEN: Este artículo trata sobre las cláusulas modificatorias de responsabilidad contractual en sus tres variantes, esto es, eximentes, limitativas y agravantes de responsabilidad. Las dos primeras son las que concentran el análisis pues son las que han provocado mayor discusión doctrinal llegándose a afirmar por algunos autores que las exonerativas no serían válidas por falta de causa. El análisis abarca el fundamento de estas cláusulas, las objeciones que se han formulados a su respecto, su clasificación, límites, efectos e interpretación. El consentimiento de la parte más débil en el marco de los contratos de adhesión, donde estas cláusulas son profusamente usadas, y conocidas como "cláusulas abusivas", concentran la última parte del artículo con referencia también a la Directiva de la Unión Europea que las regula.
\end{abstract}

Palabras clave: cláusulas modificatorias de responsabilidad, cláusulas abusivas, consentimiento.

ABSTRACT: This article discusses modification of contractual responsibility clauses in its three variants, namely, exoneration, limitation and aggravation of liability. The study focuses on the first two provisions because they are the ones that have caused more doctrinal discussion. Even some authors have asserted that exculpatory clauses would not be valid due to lack of consideration. The analysis covers the basis of these clauses, the objections that have been made regarding them, their classification, limits, effects and interpretation. Consent of the weaker party in the context of pre-formulated standard contracts, where such clauses are used extensively, and known as "unfair terms" is discussed in the last part of the article with reference also to the Directive of the European Union that regulates them.

Key words: liability modification clauses, unfair terms, consent.

\section{INTRODUCCIÓN}

En 1996 el profesor Lynn M. LoPucki de la University of Cornell publicó un artículo titulado The Death of Liability ${ }^{1}$, literalmente la muerte de la responsabilidad. No obstante que trataba en él un sinnúmero de aspectos sobre liability, su título nos llamó la atención por lo gráfico que es para representar lo que podría suceder con la

\footnotetext{
*Profesor de Derecho Civil, Pontificia Universidad Católica. Correo electrónico: jagonzac@uc.cl.

${ }^{1}$ LOPUCKI (1996).
} 
enorme cantidad de cláusulas, avisos, y hasta letreros que diariamente enfrentamos: si Ud. va a una clínica esta incluirá en el contrato que ha de suscribir en forma previa a la operación una cláusula por la que se le libera de toda responsabilidad; si lleva a sus hijos a un parque de entretenciones verá profusos letreros advirtiendo que no se responde por daños; si deja su vehículo en un estacionamiento la empresa no se hace responsable de los robos o hurtos ocurridos al interior de él; si el mismo automóvil lo lava en una de esas máquinas dispuestas para tal efecto en las estaciones de servicio volverá a encontrar los mismos avisos; en fin sería interminable la relación de la enorme cantidad de cláusulas de este tipo con que nos encontramos a diario. Y no sería de extrañar, que animado por esta profusa fiebre de irresponsabilidad, algún día viéramos un conductor salir en su vehículo con una leyenda i"No respondo por daños"!

El abuso en el uso de estas cláusulas ha ocasionado una innegable desconfianza hacia ellas y han sido fuertemente cuestionadas por un sector de la doctrina. En general, hay un juicio negativo y desfavorable que se atribuye a las limitaciones convencionales de responsabilidad.

El objeto de este artículo es analizar estas cláusulas en sede contractual. Esto porque ellas podrían tener lugar en materia extracontractual, y así dos agricultores vecinos podrían acordar que no habrá responsabilidad por los daños que sus animales pudieran ocasionar en el predio del otro. Esto, debe advertirse, no transforma la responsabilidad en contractual porque la fuente es un hecho ilícito y no el contrato. La voluntad de las partes solo ha intervenido para reglar sus posibles efectos, si es que llega a generarse. En todo caso es claro que el ámbito natural en que van a operar estas cláusulas es en el plano contractual, siendo las otras una excepción.

\section{FUNDAMENTO LEGAL Y DOCTRINARIO DE ESTAS CLÁUSULAS}

En materia contractual las cláusulas exonerativas, limitativas o agravantes de responsabilidad son validas por el artículo 1547 inciso final del Código Civil. Esta disposición, junto al artículo 1558, inciso final, establecidas como una interpretación de la voluntad probable de las partes, implican la posibilidad de que ellas puedan hacer variar la responsabilidad, llegando, según algunos, hasta suprimirla. En efecto, el artículo 1547 inciso final luego de establecer el grado de culpa de que se responde, según si el contrato reporta beneficio a uno u otro de los contratantes o a ambos, termina señalando que "Todo lo cual, sin embargo, se entiende sin perjuicio (...) de las estipulaciones expresas de las partes” y el artículo 1558, inciso final, luego de señalar el tipo de perjuicios de que se responde termina expresando que "Las estipulaciones de los contratantes podrán modificar estas reglas". Estas normas constituyen el "espacio libre" que el ordenamiento jurídico reconoce a las partes contratantes para que puedan autorregular la materia. La autonomía de la voluntad sería el principio que las sustenta. Y como en algunos casos estas cláusulas implican una renuncia también encuentran amparo en el artículo 12 del Código Civil.

Así también lo ha entendido la jurisprudencia al decir que semejantes convenciones que liberan al deudor de toda clase de responsabilidad en caso de incumplimiento 
"se basan en el principio de la autonomía de la voluntad y hallan su consagración en los artículos 1547, inciso final, y 1558, inciso 3º, del Estatuto Civil”2.

\section{OBJECIONES A LAS ESTIPULACIONES DE IRRESPONSABILIDAD}

Pero así como hay autores que validan estas cláusulas por las normas y fundamento doctrinario citados otros les restan eficacia. Las cláusulas en estudio han sido objeto de cuestionamientos tanto desde un punto de vista económico, como también estrictamente jurídico.

Respecto de lo primero se ha dicho que las cláusulas de irresponsabilidad llevan consigo, como resultado natural la pérdida de bienes que tal vez hubiera podido evitarse. El deudor que no corre riesgo alguno por su negligencia, será normalmente menos diligente que aquel que sabe que cargará con el peso de los daños causados por su culpa. Las cláusulas de irresponsabilidad "favorecen, pues, si pudiera decirse, la negligencia. Además ¿no está interesada la sociedad en que la pérdida de los bienes, que constituyen su riqueza al mismo tiempo que la de los particulares, se reduzca al mínimum? Y ¿no podría decirse que bajo este punto de vista, el orden público está interesado en que las cláusulas de irresponsabilidad no sean eficaces?"3.

En el plano jurídico Esmein luego de preguntarse ¡en qué principio basar jurídicamente el rechazo de la plena eficacia de la cláusula de irresponsabilidad? concluye que puede encontrarse su justificación en la falta de una de las condiciones de existencia de la obligación; a saber, la causa. Dice dicho autor: "Me parece que el que se presenta como aceptando, por haber puesto su firma al acto, una cláusula de irresponsabilidad que produzca pleno efecto, no ha consentido realmente en ella. ¿Cómo admitir que un contratante a título oneroso haya consentido en suministrar una prestación o hacer una promesa, cuando la otra parte estipula que ella estará libre aunque se pruebe que ella no ha hecho lo que debía y podía hacer para cumplir con la obligación que se impuso de su parte? ¿No es, acaso, la obligación la promesa de hacer lo humanamente posible, según las circunstancias, para procurar cierto resultado? Si una de las partes no está obligada ¿cómo hablar entonces, de compromiso de su parte? (...) Si el deudor está libre en caso de inejecución proveniente de su culpa, se aceptaría y se suministraría una prestación por la otra parte, sin el equivalente serio con el cual ella contaba, pues, por hipótesis, el acto es a título oneroso. En otros términos, su compromiso o su prestación, carecería, a su respecto, de causa, si se adopta, de acuer-

\footnotetext{
2 Sociedad Constructora Salfa S.A. con Fisco de Chile (1990). La cláusula en la especie señalaba: "la empresa constructora Salfa S.A., en virtud de la aceptación que de los términos de la presente resolución hace ante notario público, declara que: d) No tiene derecho a cobrar indemnización al Serviu XII Región ni podrá pedir la modificación del contrato por pérdidas, averías o perjuicios que dichos trabajos le causen, ni por alzas que puedan ocurrir en el precio de los materiales o jornales, si ello no se ha pactado expresamente, $n i$ por cualquier otra circunstancia no prevista en forma expresa para este contrato" (énfasis agregado). La empresa le imputaba al Serviu perjuicios provenientes de la demora en adquirir los terrenos donde debía construir las viviendas sociales. En igual sentido Braithwaite con Cía. Inglesa de Vapores (1930).

3 EsMein (1927) p. 52.
} 
do con nuestro modo de pensar, la concepción de la causa desarrollada por M. Capitant, según la cual, ella es, en los contratos sinalagmáticos, la voluntad de obtener la ejecución de la prestación que se le ha prometido en cambio" ${ }^{4}$. Por tanto, la noción misma del contrato sería, a juicio de Esmein, inconciliable con una estipulación de irresponsabilidad de efectos completos ${ }^{5}$. En términos similares Barros sostiene que en verdad, no puede hablarse seriamente de un contrato si el deudor está autorizado para su incumplimiento, pues, en el fondo, el contrato estaría entregado a la mera voluntad del deudor, a la manera de la condición meramente potestativa del deudor, referida en el artículo 1478 inciso $1^{\circ}$ del C.C. ${ }^{6}$. En resumen, se dice, no estaríamos en presencia de una obligación jurídica ${ }^{7}$.

\section{EL NECESARIO CONSENTIMIENTO}

Una declaración unilateral de voluntad no puede eliminar las reglas de responsabilidad. De ahí que en principio estas cláusulas no pueden considerarse existentes por el solo hecho que la clínica ${ }^{9}$, el parque de entretenciones, el estacionamiento u otro incorpore una cláusula o ponga avisos declinando su responsabilidad por los daños que se causen, a menos que se acredite que hubo aceptación de la otra parte. Si no se prueba el consentimiento habrá nulidad por falta de este.

Para que la cláusula de irresponsabilidad afecte a la otra parte es necesario que esta la haya aceptado, su fuente es el consentimiento de las partes. La aceptación puede ser expresa o tácita, pero en todo caso debe ser concluyente e inequívoca. De manera que no puede inferirse de la mera circunstancia de que esa parte haya ingresado al lugar, estacionado su automóvil, etc. ${ }^{10}$. En la duda, el tribunal debe inclinarse por su inexistencia, pues la regla general es la responsabilidad y la irresponsabilidad la excepción.

Como luego veremos, el problema del consentimiento cobra especial relevancia en materia de consumo y contratos de adhesión, donde muchas legislaciones son rigurosas y establecen una serie de cortapisas al respecto.

\footnotetext{
${ }^{4}$ ESMEIN (1927) pp. 53-54.

5 ESMEIN (1927) p. 59.

${ }^{6}$ BARROS (2007) p. 1097.

7 Véase por todos De Verda y BEAmOnTe (2005) pp. 33-34.

8 Pero otros han observado que una obligación sigue conservando su carácter jurídico no obstante la presencia de estas cláusulas de irresponsabilidad pues a la parte afectada por el incumplimiento igualmente le quedan a salvo otros mecanismos como lo son, verbi gracia, pedir el cumplimiento forzado o la resolución del contrato.

${ }^{9}$ Medina (2009) en especial pp. 66-76.

${ }^{10}$ Una relación de cómo la jurisprudencia extranjera se muestra exigente con las aceptaciones tácitas de las cláusulas limitativas de responsabilidad, especialmente si están contenidas en las condiciones generales de contratación formuladas por la empresa favorecida por dichas cláusulas en GARCÍA (1965) p. 239, nota 1.
} 


\section{CLASIFICACIÓN}

La más aceptada clasificación distingue entre:

\subsection{CláUsulas QUE agraVAN LA RESPONSABILIDAD DEL DEUDOR}

Por ejemplo:

- Hacer responder al deudor de un grado mayor de culpa.

Como si debiendo responder de la culpa leve se le impone responsabilidad por culpa levísima (caso del arrendatario), o si debiendo responder de la culpa grave se estipula que se incluirá cualquier grado de culpa (caso del depositario).

- Estipular que el deudor responderá del caso fortuito (art. 1673 del C.C.).

- Hacer responder al deudor de perjuicios de los cuales normalmente no responde.

Como si se incluyen los imprevistos aun si la presencia de dolo o culpa grave, o bien si se le hace responsable aun de los indirectos.

\subsection{CláUSUlas Limitativas DE RESPONSABILIDAD}

Pueden tener por objeto:

- Reducir el grado de culpa del deudor.

Por ejemplo, que al comodatario, en vez de responder de la culpa levísima, lo afecte solamente la leve.

- Limitar la indemnización eventual a una suma determinada.

Se puede estipular que el deudor condenado a reparar el daño no lo será a una suma superior a la que se fija de común acuerdo ${ }^{11}$.

- Limitar los plazos de prescripción.

Generalmente se reconoce la validez de estos pactos, pues a diferencia de aquellos que amplían los plazos de prescripción no implican una renuncia (cuestión prohibida por el art. 2494 del C.C.). En efecto, se dice, permitir un mayor plazo al legal es una forma de renuncia, pues podría incluso fijarse en cien años el plazo de prescripción.

Además, la validez de las cláusulas que acortan dichos plazos no queda obstaculizada por la consideración de que la prescripción es una institución de orden público, porque lo que dicha institución trata de garantizar es la seguridad jurídica, esto es, que transcurridos los plazos legalmente previstos, no puedan prosperar reclamaciones judiciales extemporáneas; y, evidentemente, la seguridad jurídica no se ve afectada cuando las partes no alargan, sino que acortan convencionalmente el plazo de ejercicio de la acción ${ }^{12}$.

- Alterar las reglas del onus probandi.

Por ejemplo, se podría estipular que el acreedor debe probar la culpa del deudor, y no este la diligencia o cuidado que la convención le impone.

\footnotetext{
11 Abeliuk hace ver la diferencia de este caso con la cláusula penal. En esta el acreedor tiene la opción de cobrar o la pena o la indemnización de perjuicios de acuerdo a las reglas generales (art. 1543 del C.C.), y si se atiene a lo primero no necesita probar perjuicios. En cambio, en la cláusula limitativa, el acreedor, salvo que se diga lo contrario, debe probar sus perjuicios, pero no puede abandonar la estipulación y cobrar otros superiores a los fijados. ABELIUK (2008) p. 850.

12 Véase por todos De Verda y Beamonte (2005) p. 63.
} 
Sin embargo, la validez de ellas se ha discutido. Un antiguo fallo de la Corte Suprema ${ }^{13}$ las declaró nulas, por considerar que las reglas del onus probandi son de orden público, y habría objeto ilícito.

La mayoría de los autores (Abeliuk, Somarriva), no obstante, les reconocen validez amparados en el inciso final del art. 1547 del C.C., precepto que contiene la presunción de culpa del deudor, y expresamente permite la alteración de sus reglas por la ley misma o la estipulación de las partes. En segundo lugar, el argumento del orden público lo consideran débil, porque en el caso está comprometido el mero interés particular del acreedor; si este, agregan dichos autores, puede eximir al deudor de la culpa leve o levísima, con mayor razón podrá tomar sobre sí el peso de la prueba, lo que es menos grave que lo anterior. El derecho a la indemnización es disponible para el acreedor, y en consecuencia nada le impide gravarse con el onus probandi14.

\subsection{Cláusulas de EXONERACiÓN DE RESPONSABILIDAD}

Son aquellas donde derechamente se pacta la irresponsabilidad del deudor en caso de incumplimiento de su obligación y la no indemnización de perjuicio alguno derivado de él.

\section{LÍMITES DE LAS CLÁUSULAS DE IRRESPONSABILIDAD}

Los límites de estas cláusulas los constituyen el dolo, el daño a las personas, la ley y para algunos también las obligaciones esenciales.

\subsection{DOLO Y CULPA GRAVE}

No se puede pactar de antemano la irresponsabilidad de una de las partes en caso del dolo o culpa grave, pues ello significaría condonar el dolo futuro, prohibido por el artículo 1465. Semejante pacto importaría autorizarla para dejar de cumplir intencionalmente o con una negligencia tan inexcusable que bien puede equipararse al hecho voluntario, lo que es manifiestamente inmoral. No es admisible que el contrato no imponga a una de las partes un mínimo de cuidado en la ejecución de sus prestaciones. Como lo ha sostenido la jurisprudencia, las estipulaciones de irresponsabilidad son válidas "con la sola limitación que no pueden eliminar la responsabilidad del infractor que actúa con dolo o culpa grave. 60) Que en efecto el artículo 1465 del Código Civil prohíbe la condonación del dolo futuro, por lo que una renuncia anticipada del mismo adolece de objeto ilícito, con arreglo a lo dispuesto en el artículo 1466 de dicho cuerpo legal y es nula absolutamente. Otro tanto acontece con la culpa lata que equivale al dolo, conforme a lo establecido en el artículo 44, inciso $2^{\circ}$, del ordenamiento que se viene de referir" ${ }^{15}$ y "de lo contrario, serían ineludibles en todo contrato las cláusulas liberatorias del dolo, con las consecuencias delictuales que se introducirían en materia contractual" 16 .

\footnotetext{
13 Nagel y Compañia con Compañia de Seguros "Sun Insurance Office" (1909).

${ }^{14}$ ABELIUK (2008) p. 851.

15 Sociedad Constructora Salfa S.A. con Fisco de Chile (1990).

16 Comercial Automotriz Miranda Limitada con Tenenge Chile E.S.I. (1989).
} 


\subsection{DAÑOS A LAS PERSONAS}

Porque la persona está fuera del comercio humano no se puede disponer de ella, ni aun con su consentimiento. La conveniencia pública, exige, además que así sea. La sociedad tiene un interés manifiesto en proteger la integridad física y la vida de sus miembros. Este tipo de cláusulas serían contrarias al orden público y a la moral. Son, así, inválidas las cláusulas de limitación o exoneración de responsabilidad por daños ocasionados a las personas (muerte o lesiones) ${ }^{17}$.

\subsection{LA LEY}

En ocasiones la misma ley expresamente excluye estas cláusulas. Así, el Código Civil en su art. 1842 declara nulo todo pacto en que se exima al vendedor del saneamiento de evicción, siempre que en ese pacto haya habido mala fe de parte suya. También la ley sobre protección al consumidor, como se analizará infra, no tolera las cláusulas de irresponsabilidad.

\subsection{OBLigaciones ESENCIALES}

Como otro límite, aunque arduamente discutido en Francia, se señala que una cláusula que limita la responsabilidad del deudor en razón de un incumplimiento a su "obligación esencial" no podría aplicarse, por privar de causa a la parte contra la cual se hace valer. En otras palabras, una cláusula de irresponsabilidad debiera ser repudiada cuando apunta a una obligación esencial ${ }^{18}$.

Es lo que también sostiene Larroumet y como ejemplo señala que en una venta, es imposible suprimir la obligación del comprador de pagar el precio o aquella del vendedor de entregar la cosa, pues el contrato perdería su fundamento y la obligación de la otra parte se encontraría sin causa, en caso de validez de esa estipulación. En este caso, agrega, la estipulación es nula, salvo si se entendiera que el contrato no es de compraventa (por ejemplo, podría ser una donación, siempre y cuando esto haya sido lo pactado entre las partes, de lo cual se puede dudar, ya que no queda justificado pactar un precio y eximir del pago del mismo). Igualmente, en un contrato de transporte es imposible acordar que el transportista no deberá transportar la mercadería ${ }^{19}$.

En alguna oportunidad nuestra jurisprudencia ha hecho similar razonamiento. Frente a un caso en que se había pactado que el porteador no respondería por los daños que pudieran sufrir las mercaderías, nuestra Corte Suprema dijo: "80 Que la validez de las estipulaciones relacionadas con la responsabilidad del porteador de mercaderías, nace de las condiciones generales que la ley establece con respecto a los contratos, esto es, de las cosas que se distinguen en toda convención y que son las de su esencia, de su naturaleza o meramente accidentales. Con relación a las primeras, ellas constituyen el contrato mismo; mas, con respecto a las que son de su naturaleza o meramente acciden-

\footnotetext{
17 Por ello no son válidas las cláusulas contenidas en los contratos médicos, contrato de transportes, actividades recreativas riesgosas, etc. en que se exime de responsabilidad a la parte prestadora del servicio en caso de daños, pues estos, justamente afectarán la vida o integridad física de las personas.

18 GENICON (2009).

19 LARroumet (1998) p. 38.
} 
tales, las partes contratantes pueden celebrar todas las estipulaciones que les convengan, siempre que no sean contrarias a las leyes, a la moral o al orden público, ya que son disposiciones de carácter supletorio. $9^{\circ}$ Que, es evidente, que es cosa esencial del contrato de fletamento el transporte de la mercadería a un lugar determinado ya que, como se ha dicho, tal obligación constituye el contrato mismo; pero las condiciones que el cargador de la nave y el naviero establecen con relación al riesgo de las mercaderías, no forman parte de la esencia del contrato de fletamento, porque cualquiera que sean estas estipulaciones, el contrato no deja de producir efecto ni degenera en otro contrato, y perteneciendo las condiciones relacionadas con las obligaciones del porteador en orden al riesgo a cosas que son de la naturaleza del contrato, las partes contratantes pueden libremente celebrar las estipulaciones que quieran en cuanto a la responsabilidad del fletante por las pérdidas, faltas o averías de las mercaderías, materia del contrato, las que deben respetarse y cumplirse por revestir ellas la calidad de una ley. 10 ${ }^{\circ}$ Que el cargador y el naviero pueden acordar las condiciones acerca de la responsabilidad por las pérdidas, faltas o averías de las que son materia del fletamento, se desprende de las disposiciones de los artículos 1547 y 1558 del Código Civil, que son disposiciones generales relacionadas con los efectos de las obligaciones y el artículo 1063 del Código de Comercio"20.

El problema que presentan las obligaciones esenciales como límite a las cláusulas en estudio es determinar cuál o cuáles obligaciones revisten este carácter en un contrato en particular. En algunos casos esa será una tarea sencilla, pero en otros claramente será un asunto de suyo complejo.

\section{EFECTOS DE LAS CLÁUSULAS}

Como señala García Amigo las convenciones de irresponsabilidad producen los efectos generales típicos del contrato, es decir, devienen lex contractus obligatoria inter partes, no, en cambio, para terceros ${ }^{21}$.

\section{INTERPRETACIÓN DE LAS CLÁUSULAS}

La generalidad de la doctrina entiende que estas cláusulas merecen una interpretación restrictiva dado su carácter excepcional al principio general de responsabilidad, interpretación que debe aludir, entre otros extremos, a las personas a las que puede ser opuesta la cláusula, a los hechos a los que se refiere y a su objeto ${ }^{22}$.

\footnotetext{
${ }^{20}$ Braithwaite con Cía. Inglesa de Vapores (1930).

21 GARCÍA (1965) p. 257.

22 Véase por todos Álvarez (1998) p. 382 y ss. Dice esta autora: "Hemos equiparado (...) las expresiones interpretación estricta y restrictiva, porque pensamos que son dos aplicaciones de una misma regla: la prohibición de la interpretación extensiva de este tipo de cláusulas contractuales. Y son dos aplicaciones porque dos son también los supuestos de hecho: si los términos son claros y precisos, el intérprete debe ajustarse totalmente a ellos sin extender la aplicación de la cláusula de irresponsabilidad a casos similares (interpretación estricta); por el contrario, si la cláusula está redactada en términos genéricos, debe conceder el menor efecto exoneratorio (interpretación restrictiva) -frente a la posibilidad de una interpretación más amplia o extensiva-. Se trata, entonces, de la misma regla pero aplicable a dos supuestos diferentes: precisión o no precisión de los términos de la cláusula”, Idem, p. 385.
} 
Dado que en muchos casos las convenciones de no responsabilidad son redactadas previa y unilateralmente por la parte a que favorecen dichas cláusulas cobra especial relevancia para su interpretación la norma del art. 1566 del Código Civil en cuanto las cláusulas ambiguas que hayan sido extendidas o dictadas por una de las partes, sea acreedora o deudora, se interpretarán contra ella, siempre que la ambigüedad provenga de la falta de una explicación que haya debido darse por ella.

\section{LAS CLÁUSULAS LIMITATIVAS O EXONERATIVAS DE RESPONSABILIDAD EN MATERIA DE CONSUMO}

Como es fácil de comparar empíricamente hay contratos en que normalmente la cláusula de irresponsabilidad no es aceptada voluntariamente, sino que se impone por una de las partes a la otra. Así sucede en los contratos de adhesión, donde la estipulación de irresponsabilidad ha pasado a ser un lugar común en muchos de ellos inclinando el equilibrio de la relación contractual a favor de la empresa. En los llamados contratos de adhesión, una de las partes presta su consentimiento a estas cláusulas sin darse cuenta o de su existencia o de su importancia y una parte hace de su voluntad unilateral la voluntad contractual. La idea de que no se ha consentido realmente en la irresponsabilidad del deudor cobra especial fuerza aquí. De ahí que la Ley No 19.496, sobre protección de los derechos de los consumidores, en su artículo 16 disponga: "No producirán efecto alguno en los contratos de adhesión las cláusulas o estipulaciones que: e) Contengan limitaciones absolutas de responsabilidad frente al consumidor que puedan privar a este de su derecho a resarcimiento frente a deficiencias que afecten la utilidad o finalidad esencial del producto o servicio".

Esta norma ha sido aplicada por la jurisprudencia en materia de estacionamientos. La empresa concesionaria desestimaba el reclamo de un conductor, al cual le habían sido sustraídas diversas especies desde el interior de su vehículo, alegando que no tenía responsabilidad, entre otras cosas, pues aparecía informado al público mediante letreros destacados en diversos lugares del mismo que la empresa no se hacía responsable de los robos o hurtos o accidentes ocurridos en él. La Corte de Santiago primero establece la naturaleza jurídica entre el usuario y la empresa concluyendo que "la relación jurídica aludida corresponde a un típico contrato de adhesión, toda vez que para el usuario no existe posibilidad de discutir cláusula o condición alguna del contrato, a tal punto que ni siquiera existe un contrato escrito. Enseguida, es igualmente indudable que esa relación contractual es de naturaleza civil para el usuario", luego "se tiene que las cláusulas de limitación de responsabilidad establecidas por el propio prestador de servicios no producen efecto alguno, de acuerdo con el claro tenor de lo dispuesto en el Artículo 16, letra (e) de la Ley No 19.496. De este modo, resulta intrascendente el aviso al que se hace referencia en la declaración de fs. 7 , en orden a la que la concesionaria no es responsable por los hurtos, robos o accidentes que ocurran al interior del estacionamiento"23.

23 Orlando González Oporto con Vinci Park Chile Sociedad Anónima (2006). En igual sentido Jorge Bazan Cardemil con Concesionaria Subterra S.A. (2007). 
Igualmente relevante para los efectos que nos interesa es lo dispuesto en la letra g) del artículo 16 de la referida ley. Dicha disposición no reconoce valor alguno en los contratos de adhesión a las cláusulas que: "En contra de las exigencias de la buena fe, atendiendo para estos efectos a parámetros objetivos, causen en perjuicio del consumidor, un desequilibrio importante en los derechos y obligaciones que para las partes se deriven del contrato. Para ello se atenderá a la finalidad del contrato y a las disposiciones especiales o generales que lo rigen...". En efecto, algunas cláusulas que no excluyen ("limitaciones absolutas de responsabilidad" como dice la letra e) citada), pero sí limitan fuertemente la responsabilidad contractual pueden quedar comprendidas en esta disposición desde que importan un desequilibrio importante en los derechos de una de las partes.

En la Unión Europea la Directiva 93/13/CEE del Consejo, de 5 de abril de 1993, sobre las cláusulas abusivas en los contratos celebrados con consumidores, establece en su artículo $3^{\circ}$ que las cláusulas contractuales que no se hayan negociado individualmente se considerarán abusivas si, pese a las exigencias de la buena fe, causan en detrimento del consumidor un desequilibrio importante entre los derechos y obligaciones de las partes que se derivan del contrato ( $N^{\circ} 1$ ) y que se considerará que una cláusula no se ha negociado individualmente cuando haya sido redactada previamente y el consumidor no haya podido influir sobre su contenido, en particular en el caso de los contratos de adhesión. El profesional [empresario] que afirme que una cláusula tipo se ha negociado individualmente asumirá plenamente la carga de la prueba ( $N$ o 2).

El Anexo de la presente Directiva contiene una lista indicativa y no exhaustiva de cláusulas que pueden ser declaradas abusivas.

Como criterio de control se establece que el carácter abusivo de una cláusula contractual "se apreciará teniendo en cuenta la naturaleza de los bienes o servicios que sean objeto del contrato y considerando, en el momento de la celebración del mismo, todas las circunstancias que concurran en su celebración, así como todas las demás cláusulas del contrato, o de otro contrato del que dependa" (artículo $4^{\circ}$ de la misma Directiva).

El referido Anexo considera abusivas, entre otras, las cláusulas que tengan por objeto o por efecto: “a) excluir o limitar la responsabilidad legal del profesional en caso de muerte o daños físicos del consumidor debidos a una acción u omisión del mencionado profesional; b) excluir o limitar de forma inadecuada los derechos legales del consumidor con respecto al profesional o a otra parte en caso de incumplimiento total o parcial, o de cumplimiento defectuoso de una cualquiera de las obligaciones contractuales por el profesional (...)"24.

El Tribunal de Justicia de la Unión Europea ha tenido la oportunidad de pronunciarse sobre varias de estas cláusulas. Por ejemplo en una ocasión refiriéndose a contratos que contenían una cláusula que atribuía competencia a los Tribunales de Barcelona, ciudad en la que no estaba domiciliado ninguno de los demandados (compradores de

${ }^{24}$ La misma Directiva entiende por "profesional” toda persona física o jurídica que, en las transacciones reguladas por ella, actúe dentro del marco de su actividad profesional, ya sea pública o privada (Art. 2º letra c)). 
enciclopedias), pero en donde se encontraba el domicilio social de las demandantes señaló: "22. Una cláusula (...) cuyo objeto consiste en atribuir la competencia, en todos los litigios que tengan su origen en el contrato, a un órgano jurisdiccional en cuyo territorio se halla el domicilio del profesional, impone al consumidor la obligación de someterse a la competencia exclusiva de un Tribunal que puede estar lejos de su domicilio, lo que puede hacer más dificultosa su comparecencia. En los casos de litigios de escasa cuantía, los gastos correspondientes a la comparecencia del consumidor podrían resultar disuasorios y dar lugar a que este renuncie a interponer un recurso judicial y a defenderse. Una cláusula de esta índole queda así comprendida en la categoría de aquellas que tienen por objeto o por efecto suprimir u obstaculizar el ejercicio de acciones judiciales o de recursos por parte del consumidor, a que se refiere el punto 1, letra q) del Anexo de la Directiva. 23. En cambio, esta cláusula permite al profesional agrupar todos los procedimientos contenciosos correspondientes a su actividad profesional en el Tribunal en cuyo territorio se encuentra su domicilio, lo que facilita la organización de su comparecencia, al mismo tiempo que hace que esta sea menos gravosa. 24. De ello se deduce que una cláusula atributiva de competencia que sea incluida sin que haya sido objeto de una negociación individual en un contrato celebrado entre un consumidor y un profesional y que confiere competencia exclusiva a un Tribunal en cuyo territorio se encuentra el domicilio del profesional, debe considerarse abusiva a los efectos del artículo 3 de la Directiva, en la medida en que, a pesar de la exigencia de buena fe, crea, en perjuicio del consumidor, un desequilibrio importante entre los derechos y las obligaciones de las partes que se derivan del contrato" 25 . La indefensión para la parte más débil que en la práctica pueden acarrear estas cláusulas ha sido puesto de manifiesto por varios autores $^{26}$.

\section{BIBLIOGRAFÍA CITADA}

Abeliuk M., René (2008) Las Obligaciones (Santiago, Editorial Jurídica de Chile) 1293 pp.

ÁlVAREZ LATA, Natalia (1998): Cláusulas restrictivas de responsabilidad civil (Granada, Editorial Comares) 490 pp.

BARros Bourie, Enrique (2007): Tratado de Responsabilidad Extracontractual (Santiago, Editorial Jurídica de Chile) 1230 pp.

De Verda y BEAmONTE, José Ramón (2005): "Las cláusulas de exoneración y limitación de responsabilidad en el Derecho español", Revista Chilena de Derecho Privado, No 4: pp. 33-80.

Esmein, M. Paul (1927): "De las cláusulas de irresponsabilidad", Revista de Derecho y Jurisprudencia, T. XXIV: pp. 47-66.

25 Océano Grupo Editorial, S.A. con Rocio Murciano Quintero y Salvat Editores, S.A. con José M. Sánchez Alcón Prades, José Luis Copano Badillo, Mohammed Berroane, Emilio Viñas Feliú (2000).

${ }^{26}$ Así, Álvarez (1998) pp. 34-38. 
García Amigo, Manuel (1965): Cláusulas Limitativas de la Responsabilidad Contractual (Madrid, Editorial Tecnos) 287 pp.

Genicon, Thomas (2009): "El régimen de las cláusulas limitativas de reparación: inventario y perspectivas”, Revista Chilena de Derecho Privado, No 13: pp. 123-159.

Larroumet, Christian (1998): Responsabilidad Civil Contractual. Algunos temas modernos (Santiago, Editorial Jurídica de Chile) $121 \mathrm{pp.}$

LoPuCKI, Lynn M. (1996): “The Death of Liability”, The Yale Law Journal, Vol. 106 No. 1: pp. 1-92.

MEdina LAÍNEZ, María Francisca (2009): Incidencia de las cláusulas modificatorias de responsabilidad contractual en la responsabilidad médica (Santiago, Tesis Pontificia Universidad Católica de Chile) 86 pp.

\section{NORMAS CITADAS}

Ley No 19.496, sobre protección de los derechos de los consumidores. Diario Oficial, 7 de marzo de 1997.

Directiva 93/13/CEE del Consejo, sobre las cláusulas abusivas en los contratos celebrados con consumidores, 5 de abril de 1993. Disponible en: http:/leur-lex.europa.eul LexUriServ/LexUriServ.do?uri=CELEX:31993L0013:ES:HTML

\section{JURISPRUDENCIA CITADA}

Nagel y Compañia con Compañia de Seguros "Sun Insurance Office" (1909): Corte Suprema, 30 de diciembre de 1909, Revista de Derecho y Jurisprudencia, tomo $8^{\circ}$, sec. $1^{\text {a }}$, p. 62.

Braithwaite con Cía. Inglesa de Vapores (1930): Corte Suprema, 2 de enero de 1930, Revista de Derecho y Jurisprudencia, tomo 27, sec. 1a, p. 724.

Comercial Automotriz Miranda Limitada con Tenenge Chile E.S.I. (1989): Corte de Apelaciones de Antofagasta, 1 de octubre de 1989, Revista de Derecho y Jurisprudencia, tomo 89 , sec. $1^{\text {a }}$, cons. 11 , p. 24.

Sociedad Constructora Salfa S.A. con Fisco de Chile (1990): Corte de Apelaciones de Punta Arenas, 26 de enero de 1990, Revista de Derecho y Jurisprudencia, tomo 87, sec. $2^{\mathrm{a}}$, cons. $5^{\circ}$, p. 25.

Océano Grupo Editorial, S.A. con Rocio Murciano Quintero (asunto C-240/98) y Salvat Editores, S.A. con José M. Sánchez Alcón Prades (asunto C-241/98), José Luis Copano Badillo (asunto C-242/98), Mohammed Berroane (asunto C-243/98), Emilio Viñas Feliú (asunto C-244/98)" (2000): Tribunal de Justicia de la Unión Europea, 27 de junio de 2000.

Orlando González Oporto con Vinci Park Chile Sociedad Anónima (2006): Corte de Apelaciones de Santiago, 16 de junio de 2006, Rol 1258-2006, cons. 7º.

Jorge Bazan Cardemil con Concesionaria Subterra S.A. (2007): Corte de Apelaciones de Santiago, 10 de agosto de 2007, Rol 3437-2007, cons. $2^{\circ}$ y $3^{\circ}$. 